servar la intervención social (en tanto oferta) para mejorarla, permite captar lo que los actores involucrados buscan y ponerlo logicamente en contacto con el Otro (usuario). Lo procedimental busca producir experiencias del mundo de una forma Otra y conexpendo los intereses de interventor e intervenido. Interroga acerca de las formas de hacer, produciendo variedad, comparación. En este sentido lo ético está puesto como una oferta trasparente que no promete lo que no cumple. Como campo tecnológico de reflexión centra su atención en el estudio de la oferta.

\section{A modo de conclusión}

En síntesis, podemos señalar que las lógicas esencialistas (ancladas en lo que denominamos siguiendo a Adorno, pensamiento identitario) y las lógicas de intervención centradas en tecnologías sociales conviven en una relación de hibridaje y, a la vez, son introducidas por las lógicas subyacentes en las formas de ver que poseen las organizaciones que implementan programas y/o los operadores (profesionales) que en estas se desempeñan.

La principal consecuencia que se extrae de esta situación, está dada por superar la visión de las intervenciones como "posibilidades únicas y suficientes para personas que no tienen otra opción". Este último ejemplo grafica la imposibilidad (para quienes así lo ven) de introducir actualizaciones (up dos esencializadamente.

Podemos señalar así, que:

- Pensar la intervención social desde un principio procedimental supone lógicas de intervención social post convencionales, esto es, ancladas en una visión postmetafísica (Habermas) del conocimiento, capaces de dotar a programas fijos anclados en formas unidimensionales de ver a anclados en formas unidimensionales de ver
los sujetos, de cualidades dinámicas, móviles, los sujetos, de cualidades dinámicas, móviles, cedimentalización de las intervenciones sociales.

Si la intervención social fuese leída como una lucha, sería una como la del David contra Goliat es que el objeto propio de quienes se afanan en social es el capitalismo y sus consecuencias hum social es el capitalismo y sus consecuencias humanas (Marroquin, 2011). Lo primero que concurre la intervención, entonces, es la adversidad. Esta excesiva negatividad demanda una alta especificidad. En otras palabras, escoger las armas y las estrategias con mucho cuidado antes de iniciar el combate.

¿Cuáles son estas herramientas? En mi opinión, las lógicas con las que se articulan las acciones que conforman las intervenciones sociales y su campo, las regiones del conocimiento.
Estos "combates regionales" se desenvuelven en movimiento, es decir, la relación entre las cosas y las lógicas no se ha de buscar en un horizonte en que no pueden ser aprehendidas de una vez y para siempre sino donde parecen responder a lo que Hegel de"En este sentido el camino de las lógicas de intervención es mortal: no es posible innovar para producir estructuras, sino que para aprender de las cosas, moviéndose junto a ellas y con ellas.

\section{Referencias}

ACEVEDO, J. (2006). Meditación acerca de nuestra época: una era tecnica. En E. Sabrovsky, La tecnica en Heidegger. Santiago de Chile: Universidad Diego Portales.

ADORNO, T., y HORKHEIMER, M. (1987). Dialéctica del iluminismo. Buenos Aires: Sudamericana.

BOURDIEU, P. (1995). Razones prácticas. Barcelona: Anagrama.

CARVAJAL, G. (2010). Observaciones historiográficas sobre el diseño de una teoría general de la tecnolog : Aristóteles Beckmann Marx y Kuhn Revista Observaciones Filosóficas. Volumen 11 Issue 1 Disponible en: http:// www observacionesfilosoficas net/observacioneshistoriograficos.htm

CHERNILO, D., y MASCAREÑO, A. (2005). Universalismo, particularismo y sociedad. Obstáculos y perspectivas de a sociología en América Latina. En Persona y Sociedad, XXIX (3), 17-45. Universidad Alberto Hurtado. Santiago. HABERMAS, J. (1990). Pensamiento postmetafisico. Madrid: Taurus.

HALL, R. (2008). Evidence-based practice as social work tecnology. Irish Journal of Social Strudies, 8 (1), 21-29. LECHNER, N. (2007). Tres formas de coordinación social. En Obras escogidas II. Santiago de Chile: LOM.

MARROQUín, A. (2011). Trabajo social como oficio imposible. Normalización, capitalismo y crítica. Revista de Trabajo Social, 80. Santiago de Chile.

MASCAREÑO, A. (2011). Sociología de la intervención: orientación sistémica contextual. Revista MAD (25). Santiago de Chile.

MATUS, T. (2000). Propuestas contemporáneas en trabajo social. Hacia una intervención polifónica. Buenos Aires: Espacio.

MATUS, T. (1995). Experiencia y pobreza en el trabajo social: una lectura frankfurteana. Revista O Social em Questao, XIII (24)

THYEGESEN, N. (2011). An introduction to understanding technology as illusions. New York: Pelgrave.

\title{
Trabajo social y relatos de vida. Reflexiones para una intervención social en dinámicas familiares abusivas
}

Social work and life stories: Reflections for a social intervention in abusive family dynamics

Patricia Carrasco Urrutia

Trabajadora social, magister en Ciencias Sociales de la Universidad de La Frontera, Temuco, Chile. Doctora en Ciencias Sociales, Universidad Iberoamericana, México D.F. México. Trabajadora Social del Centro Atención Integral a Victimas de Delitos Violentos, Coyhaique,XI Región,CChile.Email: paticau@hotmail.com

\section{Resumen}

Los relatos de vida pueden constituir una herramienta para el abordaje de casos o la intervenció profesional con familias. A continuación se presentan algunos aspectos de la sistematización de una experiencia de trabajo desarrollada con madres de niños-niñas victimas de un delito sexua intrafamiliar. Se trata de una experiencia profesional que busca traspasar los ejes de la producción discursiva explicita de las madres o figura adulta protectora que acompaña al niño o niña, en el proceso terapéutico reparatorio; $y$ busca acceder a las construcciones significantes que organizan la vida familiar de la victima y su madre, de modo que, a través de la formulación de relatos de zar los sistemas vinculares del niño-niña victima y su figura adulta protectora.

Palabras claves. Trabajo social, intervención social, relatos de vida, adulto protector, resignificar experiencias abusivas.

Abstract

Life stories can be a useful tool for professional intervention within families for social works. Thi paper presents the systematization of the work experience with mothers of children who wer victims of intrafamilial sexual abuse. It tries to go further of the explicit discursive production of mothers or of the protector adults that accompanies the abused child during the therapeutic reparatory process. Instead, this paper attempts to access the meaningful constructions that organize the everyday life of victims and their mothers through life stories. These allow to socia workers co-construct and redefine the abusive experiences and reorganize the emotional links between the victims and the protective adults

Key words. Social work, social intervention, life stories, protector adult, mind change abusive experiences.

\section{Introducción}

Los relatos de vida pueden constituir una herramienta para la intervención social con madres de niños, niñas y adolescentes víctimas de delitos sexuales de carácter intrafamiliar ${ }^{1}$. Los profesionales que participan de equipos o duplas psicosociales para el abordaje requipos o duplas psicosociales sexuales, disponen de amplia literatura para el trabajo con víctimas directas: caracterizaciones, tipos de víctimas, sintomatologías, efectos a corto y largo plazo, entre otros, y una formación profesional terapéutica; no obstante, el trabajo con la red familiar generalmente de cargo del trabajador social, dispone de menos herramientas metodológicas y de literatura especializada para dicha intervención.

En tal sentido, los relatos de vida, ampliamente usados en sociología, pueden ofrecernos una posibilida para el abordaje profesional. Bertaux (2005) sostien 
que los relatos de vida son aquellos que "cuentan la historia de una vida (....) que desde el momento en que aparece la forma narrativa en una conversación el sujeto la utiliza para examinar el contenido de un se trata de un relato de vida" (p.36).

Por otra parte, Bruner (2003) avizorando la identidad como núcleo central de esta narrativa, sostien que "la creación del Yo, es una arte narrativo (...) que creamos y recreamos la identidad mediante la narrativa, que el yo es un producto de nuestros relatos y no una cierta esencia por descubrir cavando en los confines de la subjetividad. (..) está demostrado que sin la capacidad de contar historias sobre nosotros mismos no existiria una cosa como la identidad" (p.124). Así entendidos, los relatos de vida pueden constituir una forma de aproximación al yo social que alberga la narrativa de quien la produce. Ahora bien, el trabajo con la red familiar y con una figura adulta protectora resulta de extrema relevancia para la reparación emocional de la víctima. En ta sentido, diversos estudios han coincidido en señalar que "la conducta de los miembros de la familia influye en la recuperabilidad de la víctima, teniendo en ello la madre un rol preponderante y se correlacionan directamente el apoyo prestado a la hija/o con la capacidad de recuperar niveles de actividad, menor depresión, etc." (Canton y Cortés, 1999, p. 26).

La intervención con familias que han vivido experiencias abusivas en su interior, a través de la victimización de alguno de sus miembros, resulta de alta complejidad. Sin embargo, en la literatura especializada se aprecian delimitados intentos por descifrar las dinámicas que albergan estos sistemas miliares, centrándose más en aspectos vinculados a la victima popiamente to cual ciertamente dificulta la comprension y el abordaje asertivo del fenomeno. Por otro lado, en el trabajo social las herramientas para la intervención familiar no siempre nos permiten traspasar las barreras discursivas del orden de lo explícito, y nos dejan al margen de dinámicas complejas, como aquellas que se develan en las historias de abuso sexual intrafamiliar. Contamos con elementos referenciales par un abordaje que requiere de dispositivos metodológicos, de los cuales no siempre nos encontramos provistos en nuestra formación profesional.

En tal sentido este artículo contribuye a la reflexión sobre las herramientas que disponemos para intervenir en un plano familiar de alta complejidad y de herramientas disponibles en otras disciplinas, como son los relatos de vida.

Los niños y niñas víctimas de abuso sexual intra- familiar constituyen un porcentaje relevante del universo de víctimas por delitos sexuales en Chile. Larraín y Bascuñán (2012) revelan en el último estudio realizado sobre maltrato infantil en nuestro país, que la prevalencia del abuso sexual es de un $8.9 \%$; que $175.1 \%$ de quienes jercen abuso sexul (2) son hombres; que, el $88.5 \%$ de los victimarios son conocidos de los niños y niñas; y que el $50.4 \%$ de
los agresores son familiares.

En este escenario, la intervención con la red familiar de niños, niñas y adolescentes victimizadas por un familiar, especialmente cuando se trata de la figura paterna, nos enfre (nicultades: emocionales, económicas, habitacionales, vinculares y sociales para la víctima y su familia. En lo específico, la dificultad de encontrar figuras maternas alineadas y disponibles para apoyar el proceso terapéutico reparatorio del niño-niña víctima, constituye el principal escollo en esta fase inicial de la intervención. En tal sentido, hemos observado en la práctica profesional, que nuchas madres atopada res atrapadas en dinamicas abusivas, violentas y en contextos de pobreza suelen optar por la diada conyugal, dejando al niño-niña, sin figura adulta significativa que sostenga el proceso terapéutico, marginándose de la recuperabilidad de la víctima. Restándose la madre como figura adulta protectora -en esta fase inicialtanto la literatura especializada como la experiencia profesional, recomiendan la activación de la red familiar, social e institucional disponible.

Activar la red familiar implica la pérdida de la figura materna para sostener el proceso terapéutico del niño, lo cual constituye un nuevo daño para la víctima, por cuanto implica una nueva pérdida asociada a la develación de la experiencia abusiva. La ausencia de la figura materna como sostenedora del proceso terapéutico reparatorio del hijo - hija víctima trae generalmente aparejada también, la pérdida y la salida de la víctima del núcleo familiar de origen. Lo cual, ciertamente constituye un daño grave, sino mayor a la victimización sexual. De ahí que muchos adolescentes al evaluar las consecuencias de una develación, optan por un proceso de retractación.

Así las cosas, el escenario para la intervención con familias atrapadas en dinámicas abusivas hacia sus hijos, pone de relieve la extrema complejidad para la intervención profesional de los trabajadores sociales. La figura materna es una figura central para la reparación de la víctima. Hemos observado en los años de intervención profesional con víctimas de delitos sexuales intrafamiliares, que ser creído por la madre y que luego esta sostenga la acusación penal contra el agresor, constituye de por sí un gran aporte a la reparación de la víctima. En contrario, el haber sido victimizado por la figura paterna, la falta de credibilidad de la madre y del entorno familiar, agravan y cronifican el daño de las víctimas. Por tanto, nuestoro primer esfue rar la figura materna como punto de partida de la intervención del trabajador social. Ello implica dar sostenibilidad al proceso terapéutico; evitar el daño de la pérdida de la figura materna y muy probablemente de su núcleo familiar de origen. Significa dar inicio al proceso terapéutico reparatorio aportando credibilidad y sostén familiar. Bases mínimas para la superación del trauma.

En tal sentido, este artículo propone evitar el abandono o deserción de la figura materna. Sugiere recuperar a la madre, en la medida de lo plausible, en este escenario de vasta complejidad.

\section{Familias atrapadas en dinámicas \\ abusivas}

Hemos observado en el trabajo realizado con familias atrapadas en dinámicas sexuales abusivas, en las que el padre o figura paterna abusa sexualmente de uno o más hijos al interior del núcleo familiar, el disfuncionalidades que atrapan a sus miembros en largos periodos de tiempo, cronificando los abusos, para luego dar lugar a la normalización de prácticas que contravienen las reglas mínimas de co que han establecido las sociedades desde los primeros tiempos. En tal sentido, podemos recordar los planteamientos de Levi Strauss (1998), cuando señala que la prohibición del incesto regula el funcionamiento social, marcando el paso de lo natural a lo cultural, mediante la estructuración de la sociedad. El autor sostiene: "la prohibición del incesto no es más que la afirmación por parte del grupo, de que en materia de relaciones sexuales no se puede hacer cualquier cosa; el aspecto positivo de las prohibiciones es marcar un comienzo de organización" (p.54). Los resultados de una investigación cualitativa desarrollada con madres víctimas de abusos sexuales intrafamiliares (Carrasco, 2001), refiere entre sus hallazgos que las familias que cobijan experiencias abusivas, están cruzadas por severas disfuncionalidades. Regularmente observamos pobres patrones de apego de los padres o figuras adultas hacia sus hijos, especialmente respecto de las figuras maternas. violentas, en las que recurrentemente la figura agresora ejerce violencia física severa contra la madre muchas veces también contra los hijos. Son fami- lias con empobrecidas redes sociales, con tendencia al aislamiento social y familiar, lo cual ciertamente dificulta la develación de los abusos y la acción de erceros -no miembros de la familia-, que puedan sospechar de la ocurrencia de abusos al interior de la familia.

En estas familias, "la mayoría de las madres subordinan sus necesidades a las de su marido a causa de la singularidad de sus historias y sus socializaciones patriarcales" (Barudy, 1999, p. 151). En la práctica profesional hemos observado que es la figura paterna la que define $y$ articula el funcionamien(a) por el cumplimiento de tal normativa. ellas pasan largas horas ausentes de la vida familiar, cumpliendo con extensas jornadas laborales en tanto sus parejas realizan trabajos ocasionales que les llevan a tener continuas permanencias en el hogar, encontrándose a cargo de supervisar el funcionamiento diario del sistema familiar y la salida entrada de los niños del hogar, lo cual favorece la ocurrencia de experiencias abusivas en la cotidianeidad familiar.

Autores como Barudy (1999) coinciden en señala que las madres de niños y niñas víctimas de abuso suelen ser mujeres con experiencias de vida cruzadas por vivencias de maltrato y en ocasiones, experiencias sexuales abusivas en su infancia. Po otra parte, Carrasco (2001) refiere que estas madres se han insertado tempranamente al mundo laboral presentan empobrecidos vínculos con sus familias de origen; formación de parejas a raíz de tempranos embarazos o por salidas intempestivas del hogar de origen. Junto a ello, y muy fundamentalmente, evidencian empobrecidas imágenes de sí mismas y de sus capacidades, lo que tiende a crear lazos de dependencia con sus parejas, sobre quienes han depositado imaginarios masculinos gestados en patrones de género tradicionales, fuertemente arraigados en la sociedad e individualmente apropiados y significados por ellas. Estos elementos coinciden con tipologías ampliamente desarrolladlas en torno a la violencia intrafamiliar o violencias de género desarrolladas por autores como Corsi (2006); Velásquez (2003); Kirkwood (1999) y Ferreira (1989), entre otros.

La falta de autonomía y autodeterminación, imágenes de sí empobrecidas, patrones interaccionales rígidos y jerarquizados, entre otros, fundan el escenario propicio para la ocurrencia de abusos al nterior de estos núcleos familiares. Estas caracerísticas vienen además a dificultar el proceso de develación, por cuanto el abuso se instala a con- 
dición de este tipo de funcionamiento familiar. Estos son algunos de los patrones observados por Carrasco, (2001). En tal sentido, la actitud de figura materna constituye un elemento central, tanto para acurrencia de los abusos como para la develacion y posterior resolución de los mismos. Finkheor (1980), sostiene que para que se produzca un abuso sexual deben superarse barreras. Como la in hibición externa, sin la cual existe la posibilidad de acceder al niño sin la presencia de algún otro adulto que lo proteja. La falta de supervisión del niño y la inmediatez de las relaciones familiares son factores facilitadores para la superación de esta barrera. El autor seña que "la opresín de las esposas conectada con la victimización sexual de sus hijas. [Y que] la victimización sexual puede no solo propiciarse por la ausencia materna, sino también po la incapacidad materna" (pp.177-178)

Muchas madres, dado el lugar que ocupan al interio de sus familias, no constituyen barreras protectoras para sus hijos, posibilitando en este sentido la ocurren ocurrencia del abus. No obsiante, tambien pueden constituirse en una figura central para sostener la develación y la denuncia cuando se producen; también sostener el secretismo y el silenciamiento de abuso, favoreciendo procesos de retractación. De ah la importancia de trabajar con ellas, en aras de recuperar a las familias atrapadas en dinámicas abusivas, centrando la intervención en la figura materna como un eje articulador del sistema familiar, que ocupa un posición central para empoderarlo, reorientar su funcionamiento y la protección de los hijos.

En tal sentido, como trabajadores sociales debemos desplegar estrategias de intervención que nos permitan trascender la discursividad para acceder a construcciones de sentido que favorezcan conocer el ordenamiento simbólico - subjetivo de los subjetivo de los sistemas familiares y de las madres como sujetos individuales, con las cuales poder reconstruir significados

Luego de años de intervención, reflexión e investigación social relativas a la posición de las madres de niños y niñas víctimas de abuso sexual intrafamiliar, hemos podido distinguir entre un plano de discursividad explícita y uno asociado a la cons-

trucción de sentido que organiza el funcionamiento de muchas de estas madres, que no encuentran elaboraciones discursivas disponibles socialmente que alberguen o sostengan la normalización de historias abusivas en sus contextos familiares, como transcurrir cotidiano, donde el abuso se instala al interior de la dinámica familiar como un integrante más. No hay un discurso social que permita a las madres verbalizar su acomodación a dinámicas familiares abusivas. Esto constituye una barrera para quienes trabajamos directamente con ellas, por cuanto muchas veces las prácticas de estas madres se contraponen a sus produc ciones discursivas, lo que lleva al profesional interviniente a la paradoja de intervenciones que rebotan en una discursividad carente de "sentido"

El plano discursivo explícito reproduce elaboraciones discursivas validadas socialmente, que se inscriben en la memoria colectiva, para luego circular como discurso social dado por descontado, sobre normas sociales consensuadas, sobre las cuales las sociedades han legislado, a objeto de resguardar tales preceptos morales. En el caso de Chile, queda de manifiesto con solo considerar todas las últimas modificaciones legales introducidas en materia de delitos sexuales, las que han significado un aumento de penas asignadas a cada uno de ellos

Los delitos sexuales cuentan en nuestra sociedad con un amplio rechazo social. La sociedad ha instituido sanciones legales para quienes cometen este tipo de actos, más aún si son de carácter intrafamiliar, en cuyo caso la sociedad también ha explicitado su repudio otorgando un carácter de "agravante" de responsabilidad penal cuando el abusador tiene la condición de as todia o cuidado.

\section{De la gravedad de los abusos sexuales} intrafamiliares

Todo niño o niña víctima de delito sexual requiere, como elemento primordial para su reparación, el contar con ambientes protectores una vez producida la develación del abuso. En tal sentido, la figura materna cumple un rol primordial a la hora de la

2 El concepto sentido, como se lo quiera entender, sirve para subrayar que la dimensión fáctica de la experiencia vivida nunca puede ser
comprendida en su integridad ni en sus significados simbólicos, desde el momento en que estos son formas culturalmente codificadas comprendida en su integridad ni en sus significados simbólicos, desde el momento en que estos son formas culturalmente codificadas de
representación (racional, estética, normativa, etc.) que, como tales, son siempre reductivas de la complejidad de la experiencia misma.
(Crespi, 1997, p.19)

3 Modificaciones legales en Chile, entre las que cuentan: la del 12/07/1999 LEY 19617; 14/01/2004 LEY 19927; 31/08/2007 LEY 20207;
13/08/2011 LEY 20526. Art 13 y 368 del Código intervención reparatoria con la víctima. La literatura especializada ha enfatizado que "el apoyo materno es uno de los factores significativos (si no el más) para desligar al abuso tanto de los efectos a corto como a largo plazo" (Hooper, 1994, p. 34).

Los contextos familiares en los cuales la situación abusiva es de tipo intrafamiliar complejizan la intervención, toda vez que la salida de un miembro de la familia y la desarticulación de esta, a raíz de la denuncia trae asociada la emergencia de crisis emocionales, económicas y sociales severas, más aún en contextos de pobreza. Estudios en torno al tema señalan que "la relación del abusador con la víctima en un $80 \%$ correspor en un $80 \%$ correspo $41 \%$ padres biológicos, un $18 \%$ padrastros, un $23 \%$ tíos, abuelos, hermanos, primos y en un 13,7\% lo componían conocidos y amigos no familiares" (Sanz y Molina, 1999, p. 40)

Por otra parte, otro elemento que agudiza "la gravedad del abuso está en directa consonancia con el tipo de vínculo del agresor con la víctima siendo las figuras paternas, las que lideran la gravedad del daño quiguras paternas, las que lideran la gravedad del daño

\section{La intervención profesional en \\ realidades de alta complejidad}

De este modo, la intervención con la familia se torna un elemento central en la reparación de niños y niñas víctimas de abuso. Como trabajadores sociales, nos vemos enfrentados a la necesidad de intervenir, sin contar con modelos suficientemente desarrollados. Dinámicas familiares de alta complejidad como estas, requieren de intervenciones que crucen las crisis iniciales de la revelación hasta la posterior intervención reparatoria que busca ofrecer a la víctima la recomposición y/o reinserción a un sistema familiar que otorgue protección y vínculos sobre los cuales sostener el proceso reparatorio y la superación del trauma.

Como profesionales intervinientes, debemos enfrentar las severas crisis emocionales que traen aparejadas las develaciones iniciales, las cuales se encuentran asociadas a la desarticulación del sistema familiar; sea por el ingreso del agresor a un sistema carcelario y/o por la salida de la víctima a la red familiar, social o institucional; o por la intervención institucional a que se ve sometida la familia una vez producida la denuncia, pudiéndose dar uno o todos estos a la vez; lo cual ciertamente agudiza el impacto y la crisis de la apertura del abuso.

En contextos de pobreza, hemos observado que las familias además se ven enfrentadas a severas crisis económicas que dificultan la sobrevivencia de sus miembros, enfrentando dificultades para satisfacer necesidades básicas, dado el quiebre de sus estructuras jerárquicas de tipo tradicional, intensificando las crisis emocionales, especialmente de las madres, por cuanto suelen ser ellas quienes ante la pérdid pel provedor, deben asumir la manutencion familar. Además, deben constituirse en el sostén familiar de los hijos, no solo del hijo- hija víctima, sino de los demás niños del grupo familiar, -que mucha veces sin conocer los hechos- ven desarticulada su familia, y deben enfrentar la pérdida de sus integrantes, sin llegar a comprender el por qué de ello. En este escenario, las madres deben asumir nuevamente un rol protagónico, apoyando los procesos de pérdida de los demás integrantes del sistema familiar. Vale recordar que generalmente se trata de familias en etapa de crianza, reconstituidas, en las que los hijos se encuentran en distintas etapas de la vida escolar. Al respecto, Grossman, Mesterman y Adamo (1989), sostienen que "el 81\% son hijos de mujeres que están en la etapa del ciclo vital de crianza o que recién están saliendo de ella Conseson, en su mayoría, madres de hijos pequeños dos en la adolescencia" (p. 185)

Se suma a lo anterior, la serie de demandas institucionales asociadas a la develación, en las cuales se les exige cumplir con declaraciones ante distintas instituciones, citaciones múltiples y reiteradas. Al respecto la literatura señala que "una vez que el niño se decide y cuenta lo sucedido, se produce la intervención de los profesionales y el abuso se convierte anto en un problema familiar, como en una cuestió multiprofesional. La intervención no solo influye en aspectos familiares, como el lugar de residencia de alguno de sus miembros, sino que también ejerce una influencia directa en su situación psicológica social $y$ en las relaciones familiares. Además de los aspectos criminales, de protección del niño y terapéuticos" (Canton y Cortés, 1999, p. 313).

Pasada la crisis inicial, se debe enfrentar la resolución del trauma familiar, siendo entonces fundamental el trabajo a desarrollar con las madres de estos sistemas familiares, constituidas en figuras centrales, a cargo de enfrentar la sobrevivencia y rearticulación del mismo.

\section{De la intervención del trabajo socia}

Tradicionalmente la intervención social, ha sido concebida como aquella que busca la transformación de sistemas, que debido a determinadas circunstancias, requieren de colaboración externa para restituir adecuados niveles de funcionamien- 
to; o que debido a disfuncionalidades crónicas, han llevado a sus miembros a estados de crisis que requieren la intervencion profesional, generalmente porque alguno o todos ellos han visto afectado su funcionamiento vital en distintos niveles $y$ en $\mathrm{d}$ la vida económica, emocional, física y/o social.

Desde esta perspectiva, el trabajo social entendido como "un complejo y heterogéneo universo de intereses tendencias, concepciones y contextos" (Vélez, 2003, p.68), nos plantea una intervención social vasta en alcances, difícil de delimitar y de una novale bexistentes para el abordaje en casos de abuso sexual intrafamilia en los que, "lo social" del evento, queda en nuestra manos. En tal sentido, se estima que, como trabajadores sociales estamos llamados a intervenir en distintos planos de la realidad social.

En un intento de describir la experiencia profesional con familias de niños y niñas víctimas de abuso sexual intrafamiliar, es necesario distinguir distintos niveles de intervención social. Para tales fines, se propone una primera clasificación, que busca describir y distinguir estos niveles de actuación profesional.

\section{De la trama de la materialidad que rodea las} circunstancias vitales de un sistema familiar

\section{abusivo}

Una vez producida la revelación, se recomiend hacer una evaluación de los riesgos ${ }^{5}$ para el niño víctima y su familia. La primera medida o fase, de tipo inminente, es la tendiente a interrumpir el abuso como elemento fundamental de cualquier intervención profesional. En esto hay acuerdo unánime en la literatura especializada Al respecto, que "es preciso tener la certeza de que la víctima se halla protegida en la realidad: constatar que los abusos sexuales han cesado efectivamente y que la victima está cubierta de toda presión por parte del abusador o su familia" (p.91)

No obstante lo anterior la evaluación debe abarcar distintos componentes de la vida de una familia y un individuo, los que van desde el ámbito físicomaterial a los socio-ambientales y emocionales. De este modo, en un ejercicio por categorizar la realidad social, emerge un primer nivel de tipo ma- nifiesto, donde proponemos evaluar las condiciones de materialidad que rodean la vida familiar, una vez producida la denuncia. Estas son las condiciones de habitabilidad, económicas, laborales y remuneracionales a que se deben enfrentar. Por otra parte, r la disponibilidad de red familiar, social e institucional para afrontar la crisis inicial. Hasta aquí, pareciera ser el terreno de mayor competencia profesional y el que enfrentamos con más y mejores herramientas de nuestra formación profesional.

En esta primera fase de la crisis, hemos observado en el trabajo con familias de niños victimizados por sus figuras paternas, que muchas familias enfrentan severas dificultades económicas, que obstaculizan la satisfacción de necesidades básicas. En contextos de pobreza, la pérdida de la vivienda, que en ocasiones deja a estos grupos familiares sin un hogar; las rearticulaciones del funcionamiento familiar mediante la inserción laboral de las madres; el ingreso de los niños a sistemas de extensión horaria escolar; el acoplamiento a grupos familiares extensos para vivir en condición de allegados dada la falta de disponibilidad de medios económicos que permita asumir el arriendo de una nueva vivienda para ella y sus hijos. Todo ello genera notables grados de estrés para los miembros de la familia, dadas las pérdidas que dichos cambios producen en la organización familiar y que deben ser asumidas por todos y cada uno de los miembros. Pérdida de espacio, de autonomía familiar, de tiempos compartidos para la interacción, son algunas de las consecuencias asociadas a las denuncias de abuso sexual intrafamiliar en contextos de pobreza. trabajadores sociales transitamos por distintas esferas de la realidad, pasando desde las circunstancias materiales que rodean la vida de una familia a la vida psíquica-emocional de sus miembros.

\section{Trama emocional del sistema familiar}

Cuando trascendemos la materialidad de la vida familiar, se requiere de un despliegue de habilidades y conocimientos para abordar dinámicas familiares complejas. Una vez identificado el mapa de recursos personales - familiares, ambientales y materiales de los que dispone la familia, se requiere dar paso a lo que llamaría un segundo nivel de intervención o una intervención de segundo orden, en el sentido
La evaluación de estos escenarios revela que como de lo planteado por Geertz (1994), cuando habla de la tarea del etnógrafo, que busca "comprender conceptos que, para otro pueblo, son de experiencia próxima, y hacerlo de un modo lo suficientemente bueno como para colocarlos en conexión significaponceptos de experiencia distante con los que rasgos generales de la vida social, lo que resula sin rasgos generales de la vida social, lo que resulta sin duda una tarea al menos tan delicada, aunque un poco menos mágica, como ponerse en la piel del otro" (p.77).

Trabajar con una figura emocional que sostenga el proceso terapéutico del niño- niña víctima de una agresión sexual intrafamiliar se torna un desafío para profesionales de nuestra área.

Pareciera ser que en la diversidad de alcances de nuestra profesión, el mapeo, el catastro, la caracterización de un fenómeno, se nos da como algo natural, no obstante a la hora de intervenir la trama emocional que organiza un sistema familiar, la situación se dificulta sobre todo cuando nos enfrentamos a dinámicas abusivas.

Muchas veces nos quedamos entrampados en un plano discursivo manifiesto, que alude a lo explícito, lo inmediatamente asible y claro de un texto, en el sentido de lo planteado por Molitor (1990) para quien el sentido manifiesto designa el sentido intencional atribuido por el hablante. Situarnos a este nivel discursivo en la intervención, nos margina de la comprensión de sistemas significantes, sin la cual las transformaciones mediante reconstrucciones de sentido no son posibles, relegando nuestras actuaciones a intervenciones de primer orden, retomando conceptos de Geertz (1994), cuando alude a la experiencia próxima construida sobre conceptos que "un paciente, un sujeto cualquiera o en nuestro caso un informante puede emplear naturalmente y sin esfuerzo alguno para definir lo que él o sus prójimos ven, sienten, piensan, imaginan, etcétera y que podría comprender con rapidez en el caso de que fuese aplicado de forma similar a otras personas (...) la reclusión en conceptos de experiencia próxima deja a un etnógrafo en la inmediatez, enmarañado en lo vernacular" (p. 75).

El contacto con dinámicas familiares abusivas da cuenta de entramados relacionales complejos, donde enfrentamos fenómenos descritos por la literatura especializada, como por ejemplo, procesos de atrapamiento vincular, como "el hechizo" acuñado por Perrone y Nannini (1998); organizaciones familiares disfuncionales, como las señaladas por Barudy (1999); mujeres atrapadas en dinámicas maritales violentas o de interacciones de género rígidas, como las descritas por Corsi (2006), que transforman las actuaciones en planos discursivos de primer orden o explícitos, en acciones iterativas del sistema, que a oídos de quienes se encuentran atrapados en esta complejidad, no parecen más que discursos norlo intrafamiliar no puede ser develado, atrapando a quienes lo vivencian en una doble marginalidad.

Frente a esta realidad, como profesionales, nos vemos imposibilitados de encontrarnos con ese otro atrapado en dinámicas sociales censuradas. Ese otro con quien interactuamos, muchas veces no puede dar cuenta de dinámicas relacionales que albergan y silencian actos abusivos, que han sido normalizarlos e invisibilizados. El discurso social dominante reprueba estos hechos y deja doblemente marginado a quienes se han visto involucrados en dinámicas de esta complejidad, donde se ven desprovistos de producciones discursivas que les permitan dar cuenta de ellas, produciéndose el ocultamiento de lo que verdaderamente ha tenido lugar en el interio de estos sistemas familiares.

Esta forma de comunicación nos deja atrapados como profesionales intervinientes, dado que no podemos acceder a la trama interaccional que gesta este tipo de abusos, dejando a nuestras interlocutoras -las madres-, apresadas en lo reprobado la complejidad de aquello que construyó y facilitó la ocurrencia de los abusos, para acceder luego a la posición de las madres en esta escena.

En nuestros años de intervención familiar hemos observado que en esta fase de la misma algunas mujeres repiten actos discursivos de protección respaldo a la víctima, pero en la práctica se observan actos ambivalentes que niegan o esconden el apoyo velado a los agresores, evidenciándose la ausencia de la figura parental para el trabajo terapéutico con el niño-niña víctima de abuso. No pueden nombra lo que no es autorizado socialmente, elaborando producciones discursivas disonantes de sus prácticas sociales.

Entonces, nos interrogamos como trabajadores sociales acerca de cómo traspasar esos ejes discursivos explícitos de habitantes de dinámicas familiares abusivas, que muchas veces conviven con el abuso y lo han instalado y normalizado al interior del mundo privado en el que habitan. Muchas de estas madres se encuentran inicialmente ambivalentes, atrapadas en dinámicas de violencia física y/o emocional que han coartado sus posibilidades de ejercer la maternidad, donde la ausencia de una figura masculina dificulta para ellas pensar asumir la so- 
brevivencia del sistema familiar a su cargo. Esto nos hace reflexionar respecto de la urgencia de traspasa este plano discursivo y buscar caminos para un encuentro con este otro, para reconstruir significados que permitar Son las madres las figuras adultas que sobreviven a tales dinámicas, y las llamadas a reformularlas una vez develado el abuso, explicitando y rompiendo el secreto, traspasando las barreras del silencio impuesto por el agresor, haciendo pública la disfuncionalidad privada que oprimía al sistema familiar. En este sentido, se ha observado que lo discursivo respecto de vas, especialmente de tipo intrafamiliar, a veces no alcanza para comprender las construcciones de sentido que cobijan este tipo de fenómenos, dejando a sus miembros atrapados en una normalización de lo reprobado socialmente, sin discursos sociales disponibles desde donde construirse.

Al respecto, en nuestra formación profesional no disponemos de las herramientas para trascender lo latente del discurso, que alude a "un excedent de significación objetiva respecto de las intenciones del hablante. Hay una diferencia entre las intenciones subjetivas del hablante y las estructuras latentes del texto que designa el conjunto de significaciones singularmente apropiadas de la estructura social de la que participa el narrador" (Molitor, 1990, p. 3). Por ello, al vernos enfrentados a dinámicas sociales complejas, quedamos enfrentados a discursos desalojados de sentido, que no logran dar cuenta de prácticas que, confrontadas con la norma social, aparecen desprovistas de sentido, como ocurre cuando se produce la expulsión de un hijo-hija víctima de abuso sexual intrafamiliar de su núcleo familiar piv La experiencia profesional nos ha mostrado que muchas madres, obligadas por el sistema, se ven arrojadas a la denuncia e impelidas a sostener y a acompañar al hijo-hija víctima de una situación abusiva al interior de la familia. No obstante, en el proceso evidencian signos de ambivalencia respecto de tal apoyo, desistiendo muchas de ellas en la etapa inicial o media del mismo.

En razón de esta ambivalencia y de las continuas disonancias observadas en el proceso respecto de las prácticas cotidianas que se contraponen a la discursividad explícita (visita y contacto con los agresores en los recintos carcelarios, falta de disponibilidad para el proceso terapéutico que sosteng a reparación de los hijos víctimas de abuso, etc.) nos hemos cuestionado respecto de la forma en que como trabajadores sociales nos aproximamos a esta realidad, donde recurrentemente hemos advertido que el discurso explícito no alcanza para intervenir en estos contextos sociales.

Estos elementos nos han llevado a replantear desde dónde construir una intervención social que tienda puentes para un encuentro con el otro que permita construir un trabajo social que favorezca ese encuentro en una comunidad de sentido y desde allí reconstruir prácticas que permitan sostener procesos terapéuticos para la reparación de quienes han ello sea posible.

\section{Desde dónde intervenir para resignificar} experiencias y co-construir prácticas

Tal vez un camino posible sea trabajar mediante la formulación de relatos de vida, en las que las madres puedan revisar el acontecer de sus vidas y a través de esta experiencia poder, nosotros como trabajadores sociales, acceder a la construcción de sentidos que van dejando huella en este acto dialógico.

Los relatos de vida permiten al interlocutor crear un lazo con el narrador, en el cual se trasciende lo netamente discursivo para, en la profundidad del relato, generar un encuentro con el otro; donde ese otro comparte valores, emociones, historias y aprendizajes que han ido construyendo su identidad. Este encuentro permite trascender lo normativo, para acceder a la comprensión del otro, elemento fundamental para quienes trabajamos en dinámicas abusivas con figuras adultas, que generalmente tienden a autoresponsabilizarse y a experimentar una fuerte presión y sanción social por lo ocurrido. La intervención profesional, mediante el uso de relatos de vida, emerge entonces como un puente de encuentro con ese otro, que permite trascender lo discursivo explícito para acceder a construcciones de sentido, desde donde el otro da cuenta, a través de un relato, del entramado de valores y creencias sobre los cuales se construye a sí mismo y produce sus interacciones sociales. Se propone entonces este como un escenario posible para pensar una intervención profesional con posibilidades de coconstruir significados, para reformular dinámicas familiares marcadas por patrones abusivos.

Se ha observado en la práctica profesional que en el proceso de construir un relato de vida, las mujeres van encontrándose a sí mismas, observando desde sus propios relatos, las dinámicas de violencia en que se han visto atrapadas en distintas etapas de sus vidas. La co-construcción de relatos permite al tra- bajador social problematizar dinámicas de violencia normalizadas e invisibilizadas en el transcurrir de la propia vida, evidenciando potencialidades, deseos, sueños y aspiraciones truncados en una suerte de profecía autocumplida. Permite, ademas, elementos teóricos para reflexionar y comprender el funcionamiento de dinámicas violentas y/o abusivas que han marcado sus vidas, en muchos casos con ocurrencias transgeneracionales.

Cuando alguien habla de su vida trae hasta la actualidad (y desde ella), de un modo consiente o no, fragmentos de su pasado tal y como los reconstruye desde el tiempo pres hablante se hablante selecciona recuerdos que desde el presente adquieren un sentido y una función al interior de la situación generadora de la narración y del relato mismo. Lo que se recuerda es recordado desde el presente y está compuesto por aquello que para el hablante, o para su interrogadora, hoy merece ser imperecedero. (Piña, 1989, p.148). Es en este contexto, en la situación biográfica actual del hablante y en la interacción con el profesional en el cual las dos partes adquieren estatus de persona, que es posible la coenunciación que permite reasignar significados como un acto sociodiscursivo donde hablante y profesional revisan el pasado relatado, y resignifican lo vivido. Es entonces cuando hablamos de reelaborar experiencias abusivas y sentar las bases para reconstruir sistemas vinculares dañados. Es en la interacción del narrador y el profesional, en la revisión y problematización del pasado vivido, que es posible introducir elementos que permitan releer el pasado y atribuir nuevos significados.

\section{Algunos aportes disciplinares}

\section{construidos desde la experiencia}

\section{práctica}

Pensar el trabajo social desde esta óptica conlleva necesariamente un cambio en el marco teórico y epistemológico para abordar y pensar la realidad social. El trabajo social, desde esta perspectiva, implica la comprensión del mundo como una realidad es necesario 作 vida individual, familiar y social desde una apropiación individual del mundo social, que le rodea y del cual forma parte.

Desde esta perspectiva, se pretende la instrumentalización de un trabajo social que busca comprender a otro, en tanto sujeto creador de sentido, para tender puentes que permitan co-organizar nuevas producciones significantes, que buscan promover la generación de cambios en dinámicas familiares desprovistas de elementos protectores y vinculares significativos para con sus niños. Entendiendo los sistemas familiares como espacios dinámicos y relacionales.

Esta perspectiva se contrapone a un trabajo social que evalúa la realidad social como una estructura donde la producción de sentido es de carácter nívoco y se encuentra asociada a la comunidad de valores sostenida por las sociedades dominantes. En definitiva, se trata de nuevas matrices de comprensión y abordaje disciplinar para un mundo social complejo.

De este modo proponemos algunos elementos considerar para la intervención profesional, bajo esta concepción de la realidad social:

\section{Objetivos de la práctica}

1 Recuperar las historias familiares a través de relatos de vida de las madres, buscando develar trayectorias individuales y familiares que marquen las organizaciones familiares y sus dinámicas vinculares; y desde aquí, comprender cómo ha sido posible y se ha estructurado el abuso sexual y la atribución de significados que se otorga al mismo.

2 Buscar la configuración de sentido mediante la producción narrativa libre de las madres, observando en ellas la organización de su identidad y su vida familiar. Esto permite recuperar y comprender estilos de ejercicio de la maternidad, relacionales y vinculares con los demás miembros de la familia.

3 Conocer en esta producción narrativa y relacional que se establece entre el trabajador social y la madre, expectativas genuinas ante la ocurrencia del abuso, frente a la reestructuración familiar, los hijos, el medio social e institucional.

4 Sentar las bases para, desde una intervención construida en torno a la producción narrativa buscar la generación de cambios que favorezcan la protección y reparación del niño o niña víctima de un delito sexual.

5 Elaborar pericias sociales que den cuenta de un análisis relacional de la familia, su entorno y significados asociados a la comisión del delito, basado en categorías conceptuales co-construidas con el sujeto de la pericia, revelando el contenido de los procesos, la historicidad de los mismos, los significados y representaciones sociales que organizan la vida familiar, la materialidad que rodea las circunstancias familiares y el mundo social en que se inscribe y al que adhiere el sistema familiar. 


\section{Etapas del proceso}

La intervención profesional, desde esta perspectiva se construye desde lo procesual y relacional, por lo rca un paso lineal del mismo, con un comienzo y un fin, esta da cuenta de un proceso dinámico en que las distintas etapas interactúan confluyen.

De este modo, en el proceso diagnóstico emergen elementos de intervención que convergen con el momento diagnóstico y fijan los lineamientos para el diseño de la estrategia de intervención propiamente tal.

Núcleos relevantes del proceso de intervención

a Evaluación del contexto familiar en que se devela el abuso y las circunstancias que rodean la develación inmediata y sus circunstancias.

Riesgos para el niño-niña víctima, mantención de la relación con el agresor.

ii. Evaluación del vínculo de la madre con el agresor, exploración y acogida del mundo afectivo de la madre,

iii.Crisis económicas, habitacionales, asociadas a la develación que ponen en riesgo la vida familiar.

iv. Crisis emocionales de los integrantes de la familia asociada a la develación (eventuales derivaciones psiquiátricas, acogida de miembros de la red familiar más afectados, en y manejo de la situación de crisis con el adulto protector del núcleo familiar)

v. Disponibilidad del adulto protector y posibilidades de intervención profesional con fines reparatorios para la víctima

b Exploración del significado y del sentido atribuido a la experiencia abusiva, su develación, dinámica de ocurrencia, organización del sistema familiar que facilitó el abuso, reconocimiento y/o exploración en torno a la auto-evaluación de falla protectora, sen la falla protector con el agresor, con el niño o niña, tendencia culpabilizarlo, a auto culpabilizarse, dificultades para dar credibilidad al testimonio del niño, niña, adolescente)

c Exploración en torno a la visibilización del daño asociado a la vulneración para la víctima y de las capacidades y recursos personales disponibles para contribuir a su reparación.

d Posicionamiento de la madre o figura significa- tiva frente al abuso, en cuanto sujeto individual. Exploración de la lectura que el sujeto realiza en torno a su afectación como mujer, madre, jefa de hogar, esposa, hija y demás roles sociales. Cuáles causan mayor afectación emocional y sentimien(acogida de historias de vida que significan y permiten resignificar la experiencia abusiva intrafamiliar; compartir antecedentes teóricos que explican los procesos y dinámicas abusivas, lo cual permite co-reflexionar con la madre víctima en torno a cómo la historia personal ha favorecido la ocurrencia del mismo), cómo crear desde allí resignificaciones en el mundo subjetivo, que permitan en el futuro prevenir nuevas situaciones abusivas para con los hijos y consolidar el rol protector.

Explorar el mundo subjetivo de la madre en torno a la descripción de dinámicas familiares, el ejercicio de la maternidad y la relación con los hijos, y el significado atribuido a la maternidad asociado a su propia experiencia vital, y cómo desde allí resignificar experiencias y vínculos en la medida de lo posible y deseable para la madre. Co-trazar un ruta de reencuentro afectivo con los hijos y compatibilizar con el desarrollo terapéutico del niño, niña o adolescente (favorecer la expresión afectiva, los registros comunicacionales y espacios de coterapia con el hijo-hija que favorezcan la expresión afectiva, en coordinación el/la psicóloga terapeuta).

Cabe señalar que cuando se observa un daño profundo en la madre, quien, dada su historia vital asociada a recursos personales y cognitivos empobrecidos, es posible prever escasa reversibilidad, y se debe evaluar junto al equipo profesional las necesidades emocionales y la vulnerabilidad del contexto familiar que dificultan el proceso reparatorio del niño niña o adolescentes, y buscar nuevas alternativas proteccionales $y$ vinculares.

f Evaluación conjunta de la red social e institucional disponible, como recursos de apoyo a las necesidades familiares asociadas a la reestructuración del escenario familiar, a partir de la develación del abuso. Apoyar en coordinaciones y derivaciones interinstitucionales que favorezcan la mejora de la calidad de vida, trabajando en la resignificación de satisfactores vinculados a la visibilización de necesidades de otros miembros de la familia invisibilizadas (depresiones, hacinamiento, necesidades de desarrollo personal, educación, trabajo, u otros).
Limitaciones observadas en la práctica

Como se ha venido diciendo, esta experiencia se enmarca en la búsqueda de transformaciones que traspasen los ejes convencionales de interacción, donde lo explicito-discursivo no coincide con las dinámicas relacionales observadas; esto es, interacciones vinculares parentales-filiales empobrecidas, que no otorgan la contención que requiere la víctima en su proceso reparatorio. En tal sentido, se ha planteado teóricamente que "la falta de apoyo y compromiso de la madres con el descubrimiento de ólo actúa como importante factor de presión que lleva al niño a la retractación, sino que además, cuando esto sucede, vuelve a exponerlo a la repetición del abuso, con el consecuente agravamiento del pronóstico de recuperabilidad de la víctima" (Sanz y Molina, 1999, p. 177)

En esa búsqueda de contribuir a potenciar el vínculo protector fundamental, sostener para el proceso terapéutico de reparación del niño víctima, nace la necesidad de desplegar un proceso de intervención que busca trascender lo explícito.

Las dificultades de esta experiencia radican en la disponibilidad de la madre o figura adulta protectora que acompaña a niño-niña a terapia, y realizar una producción discursiva que permita conocer el sistema de significados sobre el cual organiza su funcionamiento vital. Ello requiere de capacidades discursivas personales y de disponibilidad para compartir con otro la experiencia de vida; así como también encontrarse abierto al encuentro afectivo con el hijo-hija victimizado(a). Por contrapartida, nos enfrentamos en un número no menor de casos en que las experiencias de apego son de tipo desorganizado, en que los sistemas vinculares perpetúan patrones negligentes de cuidado, acentuados por los contextos de pobreza en que se encuentran insertos, y en los que los patrones de deprivación sociocultural suelen empobrecer los recursos personales y cognitivos de los adultos protectores, lo cual dificulta la reelaboración del mundo de significados sobre el cual han construido sus identidades, su maternidad y cotidianeidad.

No obstante lo anterior, el uso de relatos de vida en trabajo social para el abordaje de dinámicas familiares abusivas en las que existen madres disponibles para co-construir relatos que permitan resignificar historias, son sin duda logros que alientan a dar continuidad al ejercicio profesional en terrenos de alta complejidad social, como son las dinámicas abusivas. La reconfiguración de escenarios familiares, teñidos por historias de sometimiento y maltrato para sus miembros a través del empoderamiento de las madres, es sin duda un desafío en el que hay que seguir empeñándose.

\section{Consideraciones finales}

Debemos continuar reflexionando y aportando a la producción teórica e investigativa con los núcleos familiares en que uno o más hijos han sido víctima de una agresión sexual. Es fundamental seguir trabajando para desentrañar las estructuras que organizan estos sistemas familiares con miras a trabajos de prevención y de intervención reparatoria. Este artículo constituye una reflexión nacida de la experiencia profesional cotidiana, que muestra las dificultades enfrentadas en la práctica, para el abordaje de este tipo de casos en contextos de pobreza, en que la develación de situaciones abusivas al interior de las familias somete a los sistemas familiares intensas crisis emocionales, económicas, y sociales; $y$ que nos enfrenta a adultos protectores con disminuidas habilidades parentales, lo cual dificulta la recuperabilidad del daño de las víctimas.

El presente documento busca avanzar en la urgente necesidad de instalar modelos de intervención que trasciendan lo inmediato.

\section{Referencias}

BARUDY, J. (1999). Maltrato infantil, ecología social: prevención y reparación. Santiago, Chile: Editorial Galdoc.

BERTAUX, D. (2005). Los relatos de vida. Perspectiva etnosociológica. Barcelona: Ediciones Bellaterra.

BRUNER, J. (2003). La fábrica de historias. Buenos Aires: Fondo de Cultura Económica, Argentina S.A

CANTON, J., y CORTÉS, M. (1999). Malos tratos y abus sexual infantil. (3ª ed). España: Editorial Siglo XXI.

CARRASCO, P. (2001). Abusos sexuales intrafamiliares incestuosos: perspectiva de las madres. (Tesis inedita

CRESPI, F. (1997). Acontecimiento y estructura. Por una teorí del cambio social. Buenos Aires: Editores Nueva Visión.

CÓDiGO PENAL. (5 a ed.). (2005). Santiago de Chile: LexisNexis.

CORSI, J. (2006). Violencia familiar; una mirada interdisciplinaria sobre un grave problema social. Buenos Aires: Paidos.

FERRERIRA, G. (1989). La mujer maltratada. Buenos Aires, Argentina: Editorial Sudamerican

FINKELHOR, D. (1980). El abuso sexual al menor: causas consecuencias y tratamiento psicosocial. ( $6^{a}$ ed.) México: Editorial Pax.

KIRKWOOD, C. (1999). Cómo separarse de su pareja abusadora. Barcelona: Ediciones Granic 
GEERTZ, C. (1994). Conocimiento local, ensayos sobre la interpretación de las culturas. Barcelona: Col. Paidós Básica, Paidós.

GROSSMAN, C., MESTERMAN, S., y ADAMO, M. (1989). Violencia en la familia. Buenos Aires: Editorial Universidad.

HOOPER, C. (1994). Madres sobrevivientes al abuso sexual de sus niños. Buenos Aires: Ediciones Nueva Visión.

LARRAÍN, S., y BASCUÑ̃́N, C. (2012). 40 estudio de maltrato infantil. Santiago, Chile: UNICEF Recuperado public/pdf/maltrato_infantil.pdf

LÉVI-STRAUSS, C. (1998). Las estructuras elementales del parentesco. Barcelona: Ediciones Paidós Ibérica.

MINISTERIO DE SALUD DE CHILE Y FONDO DE NACIONES UNIDAS PARA LA INFANCIA. (2011). Guia Clinica para al Atención de Niños, Niñas y Adolescentes Menores de 15 años, Victimas de Abuso Sexual. Santiago, Chile. Recuperada el 05 de agosto de 2013 de http://www.minsal.c// portal/url/item/aaa27720f363a745e0400101le011120.pd

MOLITOR, M. (1990). La hermenéutica colectiva en Remy J. y Ruquoy. D. Méthodes dAnalyse de contenu et sociologie Louis.

PERRONE, R., y NANNINI, M. (1998). Violencia y abusos sexuales en la familia: un abordaje sistémico y comunicacional. Buenos Aires: Paidós Terapia Familiar.

PIÑA, C. (1989). Sobre la naturaleza del discurso autobiográfico. Revista Argumentos, México UAM-X, 7,131-160 SANZ, D., y MOLINA, A. (1999). Violencia y abuso en la familia. Buenos Aires: Editorial Lumen Hvmanitas.

VELÁSQUEZ, S. (2004). Violencias cotidianas, violencias de genero. Buenos Aires: Paidós

VÉLEZ, O. (2003). Reconfigurando el trabajo social: perspectivas y tendencias contemporáneas. Buenos Aires: Espacio.

\section{Política de juventud en Chile: Cómo enfrentar la exclusión social juvenil, una mirada desde lo local}

Youth Policy in Chile: How to confront youth social exclusion, a view from the local space

Francisca Veas Bravo

Estudiante de Ciencia Politica de la Pontificia Universidad Católica de Chile, Av.Vicuña Mackenna, 4860. E-mail: flveas@uc.cl

Daniel Castillo Mauna

Estudiante de Ciencia Politica de la Pontificia Universidad Católica de Chile, Av.Vicuña Mackenna, 4860. E-mail: daniel.castillo@ uc.cl

Resumen

A nivel latinoamericano, ha existido un auge de distintas politicas públicas de juventud, sin embargo, el problema de estas politicas radica en que plantean una visión pasiva de los jóvenes como simples beneficiarios. El presente trabajo busca aclarar esta problematica, identificando a los actores formales e informales que estan involucrados y las soluciones implementadas en torno a la política pública de juventud para el caso de Chile a nivel local, 3 temas aparecen centrales el análisis: el poder burocrático, la asesoria profesional y la canalización de las necesidades de la población

Palabras claves. Juventud, politicas públicas, política municipal, exclusión.

\section{Abstract}

There has been a rise of different public policies on youth programs at Latin American level. However the problem is that these policies have a passive view of young people as mere beneficiaries. This paper seeks to clarify this problem, identifying the involved actors and the implemented solutions for youth public policy programs for the case of Chile, at the local level, focusing specifically on the Maipú and Estación Central municipalities. In both cases an 3 themes emerged as fundamental for analysis: bureaucratic power, professional support and channeling the needs

of the population.

Key words. Youth, Public Policy, Municipal Politics, Exclusion.

\section{Introducción}

A nivel latinoamericano, las políticas públicas de juventud impulsadas por los distintos Estados "han centrado sus acciones en la educación y el tiempo libre de los jóvenes, mientras que en paralelo y en diversas etapas históricas, se han desarrollado otros modelos, centrados en el control social de sectores juveniles movilizados, en el enfrentamiento a la pobreza, desde y para la prevención del delito, y más recientemente en la inserción laboral de los jóvenes" (Rodríguez, 2000:29). El problema de estas políticas es que plantean una visión pasiva de los jóvenes como simples beneficiarios y son excesivamente asistencialistas y centralizadas, ya que la política es impulsada y ejecutada directamente desde el gobierno central.
El presente trabajo de investigación busca aclarar la problemática, los actores involucrados y las soluciones que se han dado en torno a la política pública de juventud en Chile a nivel local, y se enfoca específicamente en las comunas de Maipú y Estación Central.

En la década de los noventa se pretende dar un giro aste tipo de políticas y en ese sentido, "se ha tratado de comenzar a estructurar respuestas focalizadas en grupos juveniles concretos (asumiendo la heterogeneidad de situaciones existente), a través de estrategias que toman a los jóvenes como «actores estratégicos del desarrollo» (y no solo como beneficiarios pasivos), con enfoques descentralizados y más participativos, con la intención de promover una mayor integración social de los jóvenes a to- 